\title{
Change in Gonadosomatic Index with Ovarian Maturation in Jack-knife Shrimp Haliporoides sibogae off South-western Kyushu, Japan
}

\author{
Jun Ohtomi and Shoko Yamamoto \\ Faculty of Fisheries, Kagoshima University, Shimoarata, Kagoshima 890, Japan \\ (Received November 28, 1996)
}

Key words: gonadosomatic index, oocyte development, ovarian maturation, deep-water shrimp, Haliporoides sibogae

Jack-knife shrimp Haliporoides sibogae (Decapoda, Penaeoidea, Solenoceridae) is distributed in the Indo-west Pacific including Madagascar, Japan, South China Sea, Malay Archipelago, Australia and New Zealand. ${ }^{1)}$ Baelde $^{2,3)}$ studied the fisheries biology of this species off south-eastern Australia. In Japanese waters, this species is commercially important and is mainly caught by boat seiners in outer waters adjacent to the Kii Channel and off south-western Kyushu. ${ }^{4}$ In spite of the necessity and usefulness for the appropriate stock management of this species, biological information of $H$. sibogae related to age and size at maturity, spawning season and growth parameters have not been well documented yet.

The gonadosomatic index (GSI) has been used to study the reproductive biology of a species or population. However, this index represents only a ratio of ovarian weight to body weight without the degree of ovarian maturation. In the present study, we first classified oocytes in $H$. sibogae into respective developmental stages by the histological method, and then we examined the change in GSI with ovarian maturation for the shrimp.

Specimens were collected at depth of $370 \mathrm{~m}$ in the daytime on 27 January 1996, using a small commercial boatseine net off Satsuma Peninsula in south-western Kyushu, Japan $\left(31^{\circ} 31^{\prime} \mathrm{N}, 129^{\circ} 53^{\prime} \mathrm{E}\right)$. Thirty-five females (96.5$131.0 \mathrm{~mm}$ in body length) were fixed with $10 \%$ formalin. They were weighed with an electric balance by $0.01 \mathrm{~g}$, and whole gonads were removed from each female and weighed by $1 \mathrm{mg}$. GSI was calculated as follows: $\mathrm{GSI}=100 \times \mathrm{GW} / \mathrm{BW}$, where $\mathrm{GW}$ is gonadal weight $(\mathrm{g})$ and $\mathrm{BW}$ is body weight $(\mathrm{g})$. For the histological observation, small pieces of each ovary were dehydrated in an ethanol series, embedded in paraffin, sectioned ( $5 \mu \mathrm{m}$ thickness), and stained with Mayer's hematoxylin and eosin. Preliminarily, histological sections of oocytes were made in four regions of ovaries (the anterior and posterior regions of the cephalothoracic lobes and the anterior and middle regions of the abdominal lobes) for two females (10.95 and 12.08 in GSI). These histological sections showed similar development throughout the ovaries, so we used the sections of the anterior regions of the abdominal lobes for all females.

GSI of the present females ranged from 0.23 to 14.33 . Oocytes were classified into six developmental stages: early nucleolus stage; oocytes are small and the cytoplasm is stained with hematoxylin (Fig. 1A), middle nucleolus stage; nucleoli are located in the peripheral part of the nucleus and follicle cells are visible around the oocytes (Fig. 1B), late nucleolus stage; the cytoplasm is weakly stained with hematoxylin and thickness of the follicle layer decreases (Fig. 1C), yolk granule stage; a number of yolk granules stained with eosin are found in the cytoplasm (Fig. 1D), prematuration stage; cortical crypts are found in the peripheral part of the oocyte (Fig. 1E), maturation stage; yolk granules extensively accumulate throughout the cytoplasm and germinal vesicle breakdown occurs (Fig. 1F). Oocytes at the three nucleolus stages are previtellogenic.

The present species, $H$. sibogae, belonged to an asynchronous type of ovary that contains oocytes at various developmental stages. Therefore, each ovarian maturity stage was represented as a developmental stage of the most advanced oocytes in the ovary (Table 1). Ovaries with only previtellogenic oocytes were classified as stage I (undeveloped). There was no significant correlation between GSI and female size (body length) in each ovarian maturity stage (by simple regression analysis, $p=0.063$ for stage I, 0.110 for stage II, 0.485 for stage III, 0.078 for stage IV), which suggests that GSI is independent of female size. The mean and standard deviation of GSI for each stage was as follows: stage $1 ; 2.63 \pm 1.65(n=15), I I ; 7.06 \pm 1.75(n=8)$, III; $9.68 \pm 1.04(n=6)$, IV; $11.69 \pm 2.09 \quad(n=6)$. The homogeneity of variance was indicated by the Bartlett test $^{5)}\left(\chi^{2}=0.947, p<0.05\right)$. By the analysis of variance and the test for the mean with $95 \%$ confidence limits of the difference, ${ }^{5)}$ significant differences in mean value of GSI were revealed among ovarian maturity stages. These results indicate a significant increase in GSI with ovarian maturation.

In another penaeoid shrimp such as Sicyonia ingentis (Sicyoniidae), spawning occurs within a few days after the appearance of cortical crypts in the prematuration oocytes. ${ }^{6)}$ The appearance of cortical crypts has been also reported in some penaeid prawns such as Penaeus japonicus ${ }^{7,8)} P$. chinensis, ${ }^{97} P$. aztecus,${ }^{(0)} P$. stylirostris, ${ }^{11)} P$. monodon $^{12,13)}$ and $P$. vannamei. ${ }^{13)}$ We here defined females having oocytes with cortical crypts (i.e., stage-III and IV ovaries) as "mature females"' which would spawn within a 

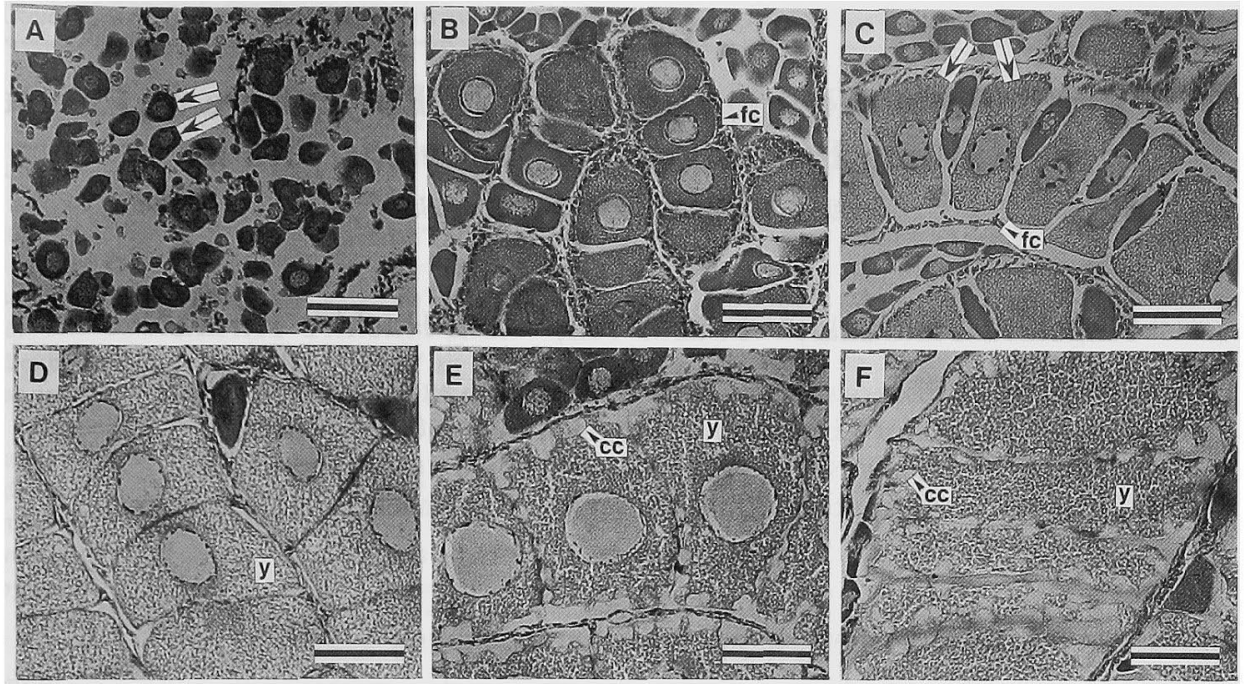

Fig. 1. Oocyte development in Haliporoides sibogae.

A; early nucleolus stage (arrows), B; middle nucleolus stage, C; late nucleolus stage (arrows), D; yolk granule stage, E; prematuration stage, F; maturation stage. fc; follicle cells, y; yolk granules, cc; cortical crypts. Scale bars $=100 \mu \mathrm{m}$.

Table 1. Ovarian maturity stages in Haliporoides sibogae

\begin{tabular}{cll}
\hline $\begin{array}{c}\text { Ovarian maturity } \\
\text { stage }\end{array}$ & Oocyte stage* & Histological condition \\
\hline I. Undeveloped & $\begin{array}{l}\text { Early nucleolus } \\
\text { Middle nucleolus } \\
\text { Late nucleolus }\end{array}$ & Previtellogenesis \\
II. Early ripe & Yolk granule & Progress of vitellogenesis \\
III. Nearly ripe & Prematuration & Appearance of cortical crypts \\
IV. Ripe & Maturation & Germinal vesicle breakdown \\
\hline
\end{tabular}

* Developmental stage of the most advanced oocytes in the ovary.

few days. Figure 2 shows the percentage occurrences of females with each ovarian maturity stage by GSI class. The mature females (III and IV) first appeared at GSI class 810 and all females with GSI $\geqq 10$ were matured. We could consider, therefore, that females of $H$. sibogae with GSI around and more than 10 roughly correspond to the mature females and they would spawn within a few days. This information will be useful for future analyses to estimate the spawning season of $H$. sibogae off south-western Kyushu using a time series of a large amount of specimens.

We would like to thank Drs. K. Nakamura, Y. Masuda and $\mathrm{H}$. Kikukawa, Kagoshima University, for their valuable comments and critical reading of the manuscript. Dr. T. Matsuoka and Mr. S. Ishizuka, Kagoshima University, and Mr. I. Nakamura, captain of the commercial fishing vessel, Chofuku-maru, helped us in shrimp sampling. Thanks are also due to anonymous reviewers for their comments and improvements to the manuscript.

\section{References}

1) L. B. Holthuis: Shrimps and prawns of the world, FAO species catalogue vol. 1, Rome, 1980, pp. 1-271.

2) P. Baelde: Mar. Biol., 113, 447-456 (1992).

3) P. Baelde: Mar. Biol., 118, 617-625 (1994).

4) K. Hayashi: Dendrobranchiata crustaceans from Japanese waters, Seibutsu Kenkyusha, Tokyo, 1992, pp. 1-300 (in Japanese).

5) Y. Fujino: in "Analysis of scientific data" (ed. by Statistics Section,

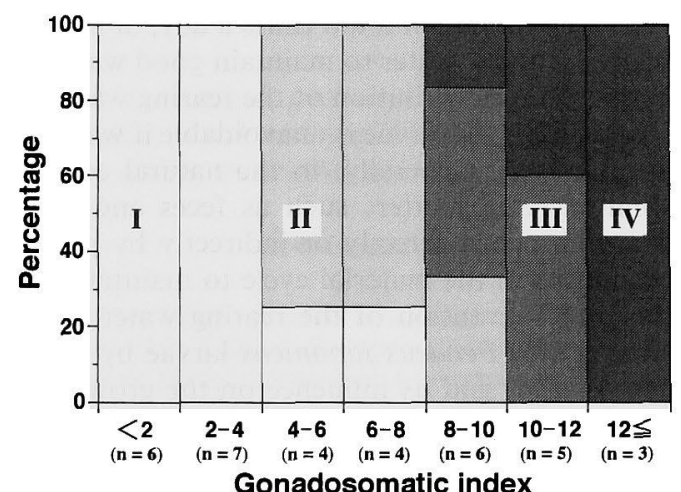

Fig. 2. Percentage occurrences of females of Haliporoides sibogae with each ovarian maturity stage by GSI class.

I; undeveloped, II; early ripe, III; nearly ripe, IV; ripe. Individuals with stage-III and IV ovaries are defined as mature females (see text).

Department of Social Science, College of Arts and Science, The University of Tokyo), University of Tokyo Press, Tokyo, 1992, pp. 79109 (in Japanese).

6) S. L. Anderson, E. S. Chang, and W. H. Clark, Jr.: Aquaculture, 42, 257-271 (1984).

7) M. Hudinaga: Jap. J. Zool., 10, 305-393 (1942).

8) I. Yano: Mar. Biol., 99, 547-553 (1988).

9) M. Oka: Bull. Fac. Fish. Nagasaki Univ., 18, 30-40 (1965) (in Japanese).

10) W. H. Clark, Jr., J. W. Lynn, A. I. Yudin, and H. O. Persyn: Biol. Bull., 158, 175-186 (1980).

11) T. A. Bell and D. V. Lightner: A handbook of normal penaeid shrimp histology, The World Aquaculture Society, Baton Rouge, 1988, pp. 1-114.

12) J. D. Tan-Fermin and R. A. Pudadera: Aquaculture, 77, 229-242 (1989).

13) R. M. Krol, W. E. Hawkins, and R. M. Overstreet: in "Microscopic anatomy of invertebrates, vol. 10 decapod crustacea"' (ed. by F. W. Harrison and A. G. Humes), Wiley-Liss, Inc., New York, 1992, pp. 295-343. 